\title{
Does the quality of encounters affect return to work? Lay people describe their experiences of meeting various professionals during their rehabilitation process
}

Ulrika Müssener, Christian Ståhl and Elsy Söderberg

Linköping University Post Print

\section{Tweet}

N.B.: When citing this work, cite the original article.

Original Publication:

Ulrika Müssener, Christian Ståhl and Elsy Söderberg, Does the quality of encounters affect return to work? Lay people describe their experiences of meeting various professionals during their rehabilitation process, 2015, Work, (52), 2, 447-455.

http://dx.doi.org/10.3233/WOR-152121

Copyright: IOS Press

http://www.iospress.nl/

Postprint available at: Linköping University Electronic Press

http://urn.kb.se/resolve?urn=urn:nbn:se:liu:diva-123175 


\title{
Does the quality of encounters affect return to work? Lay people describe their experiences of meeting various professionals during their rehabilitation process
}

\author{
Ulrika Müssener ${ }^{\mathrm{a}, *}$, Christian Ståhl ${ }^{\mathrm{b}}$ and Elsy Söderberg ${ }^{\mathrm{a}}$ \\ ${ }^{a}$ Division of Community Medicine, Department of Medical and Health Science, Linköping University, Linköping, \\ Sweden \\ ${ }^{\mathrm{b}}$ National Centre for Work and Rehabilitation, Department of Medical and Health Sciences, Linköping University, \\ Linköping, Sweden
}

Received: 23 August 2013; Accepted: 13 May 2014

\begin{abstract}
.
BACKGROUND: Among the many aspects of the rehabilitation process that may be relevant for its outcome, the impact of encounters with various professionals has received little attention.

OBJECTIVE: The objective was to gain a deeper understanding of how individuals with experiences of being on sick leave perceive their encounters with professionals, and how such encounters affected their ability to return to work, as well as their attitudes towards the sickness insurance system.

METHODS: An inductive qualitative approach was used to analyze data from 20 interviews with men and women, aged 33-59, in Sweden who had experience of being on sick leave for at least 28 days.

RESULTS: The study shows how interviewees encounters with professionals affected their self-confidence and perception of their ability to return to work. Professionals' treatment of people on sick leave seems to be affected by the structural prerequisites for offering support, where sickness insurance regulations are suggested to have a large impact.

CONCLUSIONS: An encouraging and supportive attitude on the part of the professionals is essential for empowering people to handle obstacles during the rehabilitation process; whereas feeling rejected and belittled in the return to work process may lead to disempowerment, and/or delays in measures and longer periods on sick leave.
\end{abstract}

Keywords: Sickness absence, rehabilitation, lay person, sick leave, professionals

\section{Introduction}

Detrimental effects of long-term sickness absence on individuals and society are well documented (e.g., 1). Most Western countries have carried out reforms in attempts to increase return to work (RTW) [2, 3]. In research on facilitating and hindering factors for

*Address for correspondence: Dr Ulrika Mussener, Division of Community Medicine, Department of Medical and Health Science, 58183, Linköping SE-58183 Sweden. Tel.: +46 1328 16 63; E-mail: ulrika.mussener@liu.se.
RTW, surprisingly few have examined the viewpoint of sickness absentees $[4,5]$. Notwithstanding, it can be argued that if professionals within different public organizations (such as the healthcare services, the social services, the employment- and social insurance authorities) are to succeed in developing interventions that effectively help people to return to and remain at work, it will be highly valuable to explore the experiences of the lay person [6]: in this case, the individual on sick leave. The importance of social interactions in care is often stressed [7-12], however; studies on such 
interactions cannot always be compared with studies on encounters between individuals on sick leave and rehabilitation professionals. Previous investigations, using data from both interviews [13-17] and questionnaire investigations [18-20], show that good treatment from professionals in healthcare and social insurance seems crucial for promoting sickness absentees' RTW; qualities of such encounters that have been found important are, for example, being treated with respect, and feeling supported [13, 14, 20]. Experiences of negative encounters included distant behaviour on the part of the professionals, and a feeling of being disqualified $[17,19]$. In one study it was found that the way they were treated in their meetings with healthcare professionals had the same impact on RTW as the actual rehabilitation measures provided [21]. It thus seems like encounters influences how individuals perceive their ability to work, and that the perspective of lay people is of particular value for understanding what affects behavior.

Based on the previous research on experiences of encounters with professionals, it is relevant to place focus more specifically on how these experiences may influence the individuals' ability to return to work. It is equally relevant to investigate how encounters with professionals may shape individuals' perceptions of the sickness insurance and healthcare systems, and how these systems may support them in case of illness. In this study, we aim to place focus on how encounters influence individuals' perceptions both regarding their own abilities, and toward the sickness insurance and healthcare systems.

\section{Aim}

The objective was to gain a deeper understanding of how individuals with experiences of being on sick leave perceive their encounters with professionals, and how such encounters affected their ability to return to work, as well as their attitudes towards the sickness insurance system.

\section{Methods}

\subsection{Study setting}

The Swedish sickness insurance system is tax-based and covers the working population. After a period of seven days of self-certification (i.e. that individuals reports sick to their employers), the work disability needs to be confirmed by a physician in a sickness certificate which is sent to the social insurance office. The employer has to pay $80 \%$ of wages the first 14 days (the seven first days of self-certification included) of an employee's sick leave, except for a first qualifying day. Thereafter, or by the second day if the individual is unemployed or self-employed, the Social Insurance Agency makes the decision about entitlement to sickness benefits, where eligibility criteria is based on the reduction of the individual's work ability. This is assessed based on the physician's certificate, where the work ability may be considered to be reduced with 25 , 50,75 or $100 \%$. Work ability is further assessed differently over time: within the first 90 days, the work ability is assessed in relation to ordinary work; after 90 days, in relation to any available job for the same employer; and after 180 days, in relation to any job in the labour market. If eligible, benefits may be paid out for a maximum of 365 days with about $80 \%$ of previous wages, plus an additional maximum of 550 days with reduced benefits after a renewed application. After this, sick pay is no longer granted, and the individual is transferred to the Public Employment Service for a work life introduction. It is possible to apply for disability pension, but this is only granted to those where the work ability is assessed to be permanently reduced, related to any job on the labour market.

Medical rehabilitation is most often offered by primary healthcare centres or hospitals, while work rehabilitation is carried out in the workplace where the responsibility lies with the employer.

\subsection{Selection of respondents}

The participants in the study were identified through an ongoing survey where the study sample consisted of 2500 individuals who in 2011 were aged 20-60, had varying types of employment, professions, and socioeconomic status and 1) had an ongoing spell of full- or part-time sick that had lasted for at least 28 days (i.e. receiving sickness benefits, excluding those on disability pension, parental allowances or other benefits), or 2) had returned to work full- or part-time after having received sickness benefits. The sample was drawn from a register compiled at the statistical unit of the Social Insurance Agency (the national authority administering the sickness insurance system) that included all people who fulfilled the mentioned criteria. Of the 954 respondents in the survey, 243 persons (about $25 \%$ ) accepted to take part in a complementary interview, and had filled 
Table 1

Participants in the interviews

\begin{tabular}{|c|c|c|c|c|c|c|}
\hline Interviewee & Age & Gender & Diagnosis & RTW & Employer & Work tasks \\
\hline 13 & 33 & $\mathrm{M}$ & Musculoskeletal disorder & No & None & None \\
\hline 12 & 35 & M & Musculoskeletal disorder & Yes & Same & Same \\
\hline 18 & 56 & & Musculoskeletal disorder & Yes & New & Same \\
\hline 8 & 56 & $\mathrm{~F}$ & Musculoskeletal disorder & Yes & Same & Same \\
\hline 20 & 40 & M & Musculoskeletal disorder & Yes & Same & Same \\
\hline 1 & 41 & M & Mental disorder & Yes & Same & New \\
\hline 19 & 45 & $\mathrm{~F}$ & Mental disorder & Yes & Same & Same \\
\hline 7 & 45 & M & Mental disorder & Yes & Same & Same \\
\hline 17 & 30 & M & Mental disorder & Yes & New & New \\
\hline 16 & 53 & $\mathrm{~F}$ & Other & Yes & Same & Same \\
\hline 2 & 53 & $\mathrm{~F}$ & Other & No & Unemploy & None \\
\hline 3 & 56 & $\mathrm{~F}$ & Other & Yes & Same & Same \\
\hline 4 & 50 & $\mathrm{~F}$ & Other & Yes & Same & Same \\
\hline 5 & 51 & $\mathrm{~F}$ & Other & Yes & Same & New \\
\hline 6 & 29 & $\mathrm{~F}$ & Other & Yes & Same & Same \\
\hline 9 & 44 & $\mathrm{~F}$ & Other & No & Same & Sickness absent \\
\hline 10 & 54 & M & Other & Yes & Same & Same \\
\hline 11 & 44 & $\mathrm{~F}$ & Other & Yes & Same & Same \\
\hline 14 & 59 & $\mathrm{~F}$ & Other & Yes & Same & Same \\
\hline 15 & 41 & $\mathrm{~F}$ & Other & Yes & New & Same \\
\hline
\end{tabular}

in their name, address and telephone number on the last page of the questionnaire. Letters were sent out by mail to 30 randomly chosen persons, in which respondents interested in participating were informed about the purpose of the interview study and that participation was voluntary. A consent form was enclosed with the letter, to be returned by the respondents. Of the 30 persons contacted, 20 agreed to participate. The respondents were contacted by phone and appointments for telephone interviews were set.

The interviewees were between 29 and 59 years of age, and had been put on sick leave due to the following diagnoses: chronic muscular pain and arthrosis (musculoskeletal disorders), depression and anxiety (mental diagnoses), cancer, thrombosis, renal failure, and lung disease (others). At the time of the interviews, seventeen of the participants had returned to work, two were on sick leave and one was unemployed (Table 1). Among the ten non-respondents in the survey, no distinguishing qualities could be found regarding sex, age or type of employment.

\subsection{The interview process}

An interview guide $[22,23]$ was developed based on findings in previous studies $[13,14]$ and on experience and discussions in the multi-professional project group. The interviews were semi-structured, with mainly open-ended questions, which allowed the respondents to speak freely about their situation during sickness absence and their experience of meetings with various professionals. Before the interview, the interviewer explained the purpose and the participant was informed that he or she could withdraw at any time. They were asked to talk about their experiences of encounters with various professionals during their sickness absence, to explain and describe how they perceived such encounters, and how encounters with professionals had influenced their perception of their work ability and their attitudes towards the sickness insurance system. The 20 interviews were conducted by phone in the spring of 2011 and lasted up to one hour each. All interviews were audio-taped and transcribed verbatim

\subsection{The analysis process}

An inductive qualitative approach, moving from specific observations or measures to broader generalizations or theories, was used to structure the data in order to allow themes to emerge from patterns found in the interviews without presupposing what the important dimensions would be. This also facilitated identification of multiple interrelationships among dimensions that might emerge from the data without making prior assumptions or specifying hypotheses [23]. Initially, the interviewer (the first author) listened to the tapes to ensure that the transcriptions were correct. After that, all expressions concerning the interviewees' experiences of encounters with professionals, how encounters had influenced their perception of their work ability, and 
their attitudes towards the sickness insurance systems, were identified. Patterns were searched for in the identified quotations, and categories were formed, where an emergent distinction made by the respondents was how the encounters were related to both interpersonal and regulative (structural) factors. Thereafter, the other authors read a number of interviews to validate that the initial selection of statements were representative of the material. The chosen statements and suggestions of the outlined categories were then discussed until agreement was reached on which statements to include. In the second step, the categories were iteratively compared to earlier studies and theories [24], where specifically a model used in a previous study [25] was found useful after some modifications. The present study thus includes inductively derived additions to this model.

The findings are illustrated by selected quotations, in which omitted words are indicated by $/ \ldots /$, and clarifications provided by the authors are enclosed in brackets. The interviewees were assigned individual numbers that are referred to after the quotations in the text.

The Regional Committee for Research Ethics at Linköping University approved the study.

\section{Findings}

The encounters described took place in different contexts: an administrative insurance context when applying for sick-leave benefits, a workplace context when discussing possible use of work capacity, and a medical context when talking about treatment and rehabilitation. Professionals in healthcare, occupational healthcare, social insurance, unemployment services and social services were mentioned in the statements. The presentation of the findings is structured from an inductive categorization of the material, where the respondents' described encounters with regard to interpersonal and structural aspects, and their importance for RTW.

1) Interpersonal aspects of encounters

The first category refers to perceived qualities of interpersonal aspects of the encounters. The statements were assigned to three subcategories: a) level of support, b) perception of demands, and c) establishment of a personal relationship.

\section{1.a Level of support}

This subcategory comprised aspects of engagement on the part of professionals. Experiences of being listened to and supported were frequently mentioned in the interviews. The respondents felt that it was essential that the professionals showed sympathy by not hurrying through consultations.

One woman stated that professionals within both the healthcare- and the social insurance system supported her by not questioning her story or disorder, and she stressed the importance of being listened to:

My contact at the social insurance office was a super-human! She was so nice and she took the time to listen to me. (Participant 3)

Interviewees also described encounters that were characterized by lack of involvement and concern. They described such encounters in terms of being treated in a nonchalant manner: they felt that their problems were not taken seriously or were disregarded, or that the magnitude of the problems was underestimated. One of the female participants recounted a meeting with a social insurance officer:

People like her shouldn't work with sickness absentees. She was the worse person I've ever met, because she just didn't listen, she didn't give a damn. (Participant 13)

\section{1.b Perception of demands}

The interviewees reported feelings of being encouraged when the professionals they met made wellbalanced demands, requiring neither too much nor too little of them; opinions as well as experiences differed regarding where to draw that line. If too great an effort was demanded, particularly by doctors, this sometimes resulted in confusion or disappointment. The stories were full of contradictions: some expressed the importance of being involved in the course of their own rehabilitation in order to influence their situation, but still not wanting demands to be placed upon them. For instance, when asked about the most important quality in professionals, one interviewee answered:

That they let me make my own decisions. (Participant 6)

However, in the next breath, when she continued to describe a meeting where the doctor made the decision for her, she expressed relief:

It felt really nice when they took responsibility for me. (Participant 6)

This illustrates the ambivalence that some interviewees felt towards demands, where both too little as well as too many were perceived as troublesome. This points both at the importance of demands being well-balanced, 
and the importance of how demands are communicated, which is a balancing act that is part of professional practice.

1.c Establishment of a personal relationship

Encounters where professionals were perceived as being personally involved were experienced as confirming and strengthening. A display of some degree of personal involvement by the professionals, for instance when they departed from their roles as experts and talked about other things than medical issues or sickness absence was described as an appreciated quality. Some interviewees explained their contacts with healthcare professionals as follows:

They're really kind-hearted and like a friend or something. They're absolutely lovely, these people, I must say. Yes, they treat you like a person, like a normal person. (Participant 3)

However, there were also reports of the opposite: contacts where the interviewee felt as if they were treated in a routine manner without any personal involvement. The following statements illustrate meetings with social insurance officers:

Well, I think, they're simply not familiar with my situation. They don't really care about me, or the fact that every person is an individual. I might want it one way, but another person might strive for something else. (Participant 4)

\section{2) Structural aspects of encounters}

The second category concerns the sickness insurance- and healthcare systems. The way in which professionals treat people on sick leave seems to be affected by their working conditions, which in turn are highly influenced by the context in which they operate. Sickness absentees commonly perceived the sickness insurance system as difficult and unfair, and that regulations affected encounters with social insurance officers in a negative manner: they neither had time to think nor to listen. Most interviewees were however critical of the system rather than of the professionals working in it:

I was given a sermon on all the sickness regulations. That really made me tired and fed up. It seems to me that they're completely governed by rules, they are so extremely inflexible/ .../ they're probably under a lot of pressure and understaffed, so they have no time to reflect and think for themselves. (Participant 1)
Several of the interviewees noted that the time limits in sickness insurance resulted in social insurance officers pushing sick-listed persons back to work. One individual experienced that her work capacity was still reduced, but that no attention was paid to this since the encounter was perceived as a matter of routine:

They (the Social Insurance Agency) have their regulations, and the individual doesn't matter. This full-time sick-listing period was in fact a bit short. (Participant 4)

A few interviewees felt supported by the social insurance officers, and did not recognize difficulties that others reported.

Many interviewees experienced that the different actors' had different perspectives, with lacking communication between them, and that they as sick-listed fell somewhere in between them.

The employment officers just don't understand. "Two healthy hands are what you need to get a job", but I don't have that. It will be interesting to see where I end up this time. The social insurance office claims that I need surgery. (The doctor) say that it is not possible to have surgery - I did ask. /.../ My employer behaved like two different people. To begin with she seemed so understanding, and the next moment she was just pushing. It was difficult to get a doctor's certificate, and when I couldn't get that in time, she got furious. (Participant 19) RTW

3) Quality of encounters and their importance for

Generally, the interviewees thought that the quality of the meetings with professionals was important for their motivation and ability to handle obstacles during the rehabilitation. The interviewees reported on several interactions with various professionals where they perceived that their strengths, capacities and abilities were stressed. Others felt distrusted and abandoned, which was perceived as leading to delays in RTW.

A female interviewee recalled an encounter with a social insurance officer and a doctor where she felt strengthened and motivated to return to work after the professionals listened to her solutions and believed in her capacity. This contact was made after a long period of sickness absence due to mental disorder:

They understood and they listened to what I said and took me seriously. When I told them that I wanted to try again, that I wanted to give it a go / . . / they understood that I wanted to. So I think there was a 
lot in the actual encounter both from their side and from mine that made it possible for me to go back to work. (Participant 17)

An encouraging and supportive attitude from healthcare professionals was expressed as being important for the interviewees' ability to find the stamina to contend with difficulties. One woman described how she reacted when she finally met a physician who was interested and took the time to listen to her problems, experiencing this as empowering in her return-to-work process:

It was very positive because with her as a doctor, or at least her support, maybe I would try again to get through a period of sick leave. Without that encounter nothing would have happened. I would have been unemployed without sickness benefit just like the last ten, fifteen years. (Participant 18)

The same respondent described earlier experiences of encounters with physicians which had the opposite effect, where she felt disempowered and not motivated to return to work:

They belittle you so that you feel bad when you leave and you realize that this is something I will definitely not do again. It's a waste of time and then on top of it all they actually make you pay for them to sit there and degrade you. (Participant 18)

Where interviewees were critical of the way they were treated by various professionals they also claimed that such meetings actually hindered or delayed RTW through lack of trust and a feeling of being rejected and belittled:

Yes, the lack of interest has hindered me all along.

Last spring I was sick-listed two months extra to process my request to adjust my work according to how well I felt. (Participant 1)

Another interviewee described a meeting with her doctor when she experienced being treated in an offhanded way, leading to many further contacts in order to get over her bad experiences. She recalls an incident at the hospital:

... I almost fell apart completely at that moment. Left all alone, I cried my eyes out in despair and nobody was anywhere nearby. Deserted. You see, it was so awful being treated in that way, but we dealt with that situation later. Over a long period of time after the operation I had many conversations, both alone with a counsellor, and we also met with the other doctor together. (Participant 14)
Negative encounters had a double effect of both disempowering the individual in terms of lack of motivation for returning to work, and of inducing delays in the process by reluctance to initiate measures. Ultimately, negative encounters in some cases were perceived as promoting disability rather than ability:

Actually yes, I think it was terrible, it was definitely not good. Even though I was cured, that encounter made me very ill. (Participant 2)

\section{Discussion}

\subsection{Effect of encounters on self-evaluation and work ability of sickness absentees}

Work ability is a concept that describes the interplay between individual characteristics such as health, education and motivation, and contextual factors such as possible workplace adjustments $[26,27]$. It is reasonable to assume that a person's self-evaluation of their work ability and motivation to return to work is influenced by encounters with professionals during the rehabilitation process, which may contribute to either strengthening or weakening this self-evaluation, influencing the chance of returning to work.

A previous study [25] described how the relationship between encounters, motivation and social emotions of pride and shame engage people in positive or negative loops, where the encounter may be perceived as either empowering or disempowering for the individuals' perceptions of their chances of returning to work. Pride and shame are social emotions that have been suggested to be particularly important for individuals' self-image. They involve negative or positive self-monitoring and self-evaluation, and are linked to very different behavioural tendencies [28, 29]. The sickness absentee's self-evaluation may therefore be critical to the success or failure of the rehabilitation process. Experiencing shame might lead to a self-evaluation where a person feels inadequate, unsuccessful, or unsuitable; whereas pride follows from the perception of a successful, sufficient, or adequate self [30]. These feelings were expressed also by respondents in this study, for example when interviews reported on interactions with professionals where they perceived either strengthened, or distrusted and abandoned, with consequences for the RTW.

In this study, we would like to propose a development of this model, which acknowledges a combination 


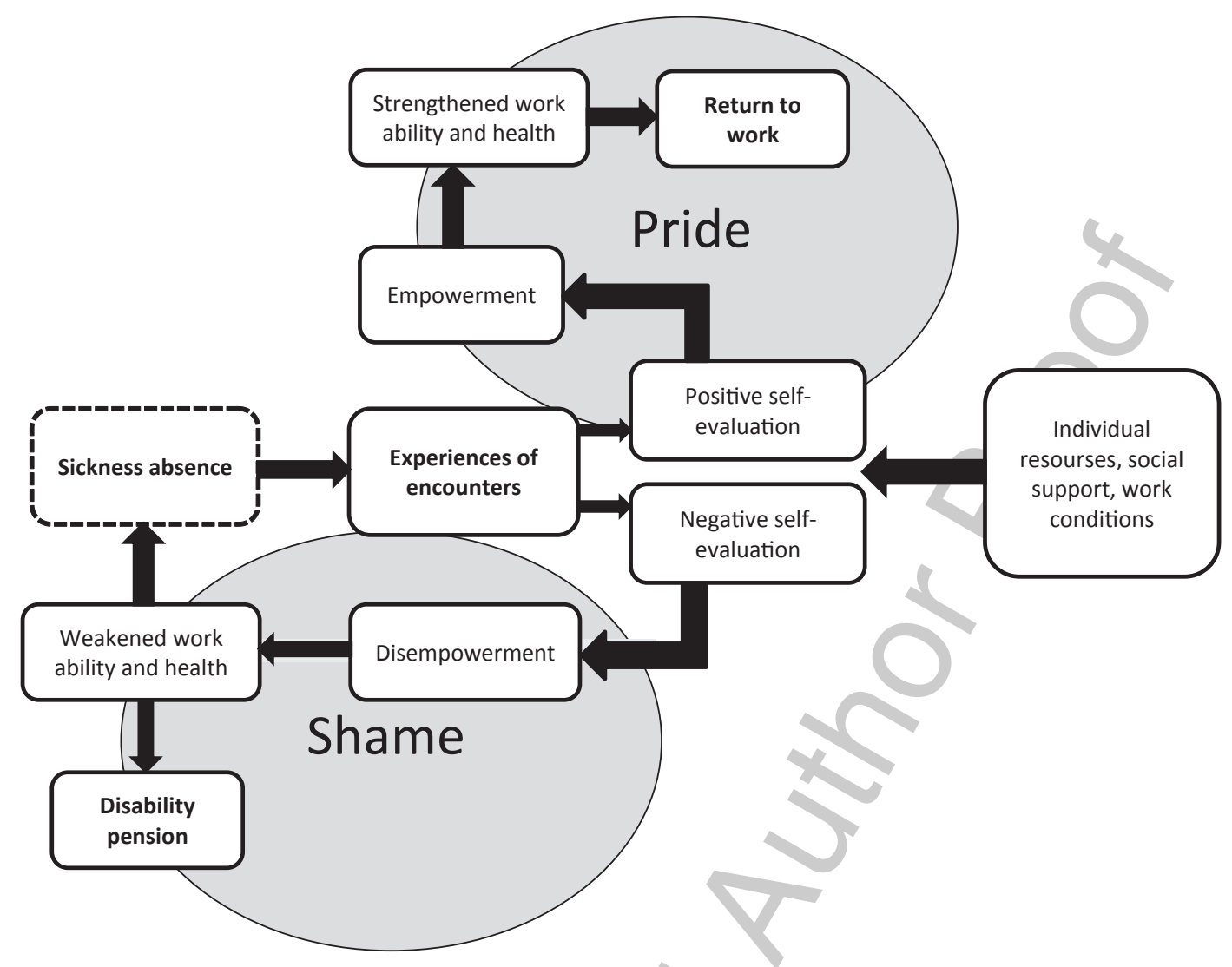

Fig. 1. Model of relationships between encounters, social emotions, empowerment, health and return to work.

of professional encounters, individual resources, social support and work conditions to be influential for determining the prospects of returning to work (Fig. 1). The findings show how the professionals need to balance the demands they place on the sick-listed, and since different people with different resources and background may perceive similar encounters differently, the balancing act is a difficult one. Encounters are not classified as positive or negative per se in the model; it is the individual's experience of the encounter that determines how this is valued.

\subsection{The interplay between individual resources, structural conditions and encounters}

Structural aspects of the encounters (e.g. sickness insurance regulations), may be an obstacle for social insurance officers' possibilities for offering suitable measures based on individual needs when these do not rhyme with the regulations. Thus structural aspects of encounters influences, and may sometimes overshadow, interpersonal aspects, and lead to negative experi- ences of encounters. Such experiences were generally attributed to the system rather than to the professionals working in them; the sick-listed persons expressed understanding of the complexities involved in the professionals' application of harsh regulations, although some were clearly upset by what the perceived as nonchalant treatment from insurance officials. Several of the interviewees stressed that the time limits in the sickness insurance system resulted in too short periods of sick leave and little time to heal. These statements should be related to recent changes in the social insurance system, where time limits for work ability assessments were introduced, alongside guidelines for physicians with recommended sick-leave periods for different diagnoses. After the implementation of these guidelines, periods of sick leave became shorter, while information related to patients' work capacity and to the workplace was still very limited and remained at the same level as before the implementation of guidelines [31].

Conditions for successful RTW vary, as does the extent to which RTW interventions are purposeful, due 
to people's diverse resources [32]. Previous studies have shown that socioeconomic position influences whether people receive disability pension or continue working [33]. It is reasonable to assume that these factors are also important for the way in which a person experiences encounters with professionals. The interplay between insurance regulations, encounters with professionals, and peoples' personal and work-related resources, is likely to influence whether the rehabilitation process is experienced as empowering or disempowering. Since negative meetings are likely to lead to new contacts, and/or delays in measures and longer periods on sick leave, interaction need to be individualized to meet the person's communication preferences and styles.

\subsection{Methodological considerations}

All participants had varying experience of being on sick leave and the majority had returned to work. Participants were chosen to ensure that there would be contrasts and variation in regard to experiences related to being on sick leave and factors effecting RTW, with variation in age, gender, socioeconomic status and diagnosis [22]. The majority of the participants were female, which is reflected in the greater proportion of female long-term sickness absentees. A limitation of the study may be the small sample. However, validity in qualitative studies is closely associated with the choice of design, where the richness of the information held by those being interviewed is more important than the sample size [23]. To ensure the validity of the findings, several steps were taken [34]. The interview guide had been previously tested in a pilot study (unpublished) to confirm that the questions were easy to understand and inspiring to answer. The interviewer had experience in the research area and of field investigations of patients receiving care. Separate readings of full interviews by the three authors were carried out to make sure that the data selected for analysis were representative of the material.

People's previous experiences, expectations and perceptions, together with other circumstances, might also influence how encounters were experienced. Here, the main purpose was to illustrate the participants' own accounts of their experiences, not to identify or discuss the reasons behind them.

\section{Conclusions}

This study illustrate how the interplay between insurance regulations and rules, encounters with various professionals, and peoples' personal and work-related resources, influence whether the rehabilitation process is experienced as profitable from a lay perspective. An encouraging and supportive attitude on the part of the professionals is essential for empowering people to handle obstacles during the rehabilitation process; whereas feeling rejected and belittled in the meeting may lead to disempowerment, and/or delays in measures and longer periods on sick leave. This knowledge is useful for developing professional strategies and attitudes that enhance self-confidence in people on sick leave, since such strengths might lead to increased opportunities for returning to work.

\section{Acknowledgments}

The authors wish to thank the interviewees for generously allowing us to explore their experiences of being on sick leave.

\section{Declaration of interest}

The study was funded by the Swedish Council for Working Life and Social Research.

\section{References}

[1] Waddell G, Burton K. Is work good for your health and well-being? Cardiff \& Huddersfield: Cardiff University \& University of Huddersfield; 2005.

[2] Auer P, editor. Security in labour markets: Combining flexibility with security for decent work. Geneva: International Labour Office (ILO); 2007.

[3] Prinz C, Tompson W. Sickness and disability benefit programmes: What is driving policy convergence? International Social Sequrity Review 2009;62:41-61.

[4] Whitaker S. The management of sickness absence. Occupational and Environmental Medicine 2001;58(6):420-4.

[5] MacEachen E, Clarke J, Franche R-L, Irvin E. Systematic review of the qualitative literature on return to work after injury. Scandinavian Journal of Work, Environment and Health 2006;13:257-69.

[6] Popay J, Williams G. Public health research and lay knowledge. Social Science \& Medicine 1996;42(5):759-68.

[7] Blasi Z, Harkness E, Ernst E, Georgiou A, Kleijnen J. Influence of context effects on health outcomes: A systematic review. The Lancet 2001;357:757-61.

[8] Luban-Plozza B. Empowerment techniques: From doctorcentred (Balint approach) to patient-centred discussion groups. Patient Education and Counseling 1995;26:257-63.

[9] Verheul W, Sanders A, Bentsing J. The effect of physicians' affect-oriented communication style and raising expectations on analouge patients' anxiety, affect and expectancies. Patient Educ Couns 2010;(80):300-6. 
[10] Charlton C, Dearing K, Berry J, Johnson M. Nurse practioners' communication styles and their impact on patient outcomes: An integrated literature review. Journal of the American Academy of Nurse Practitioners 2008;20(7):382-8.

[11] Say R, Murtagh M, Thomson R. Patients' preferences for involvement in medical decision making: A narrative review. Patient Educ Couns 2006;60(2):102-14.

[12] Griffin S, Kinmonth A, Veltman M. Effect on health-related outcomes of interventions to alter the interaction between patients and practitioners: A systematic review of trials. Ann Fam Med 2004;2:595-608.

[13] Klanghed U, Svensson T, Alexanderson K. Positive encounters with rehabilitation professionals reported by persons with experience of sickness absence. Work: A Journal of Prevention, Assessment \& Rehabilitation 2004;22(3):247-54.

[14] Müssener U, Söderberg E, Svensson T, Alexanderson K. Encouraging encounters: Sick-listed persons' experiences of interactions with rehabilitation professionals. Social Work in Health Care 2006;46(2):71-87.

[15] Nilsson M, Olsson M, Wennman-Larsen A, Petersson L-M, Alexanderson K. Return to work after breast cancer: Women's experiences of encounters with different stakeholders. European Journal of Oncology Nursing 2011;15:267-74.

[16] Svensson T, Müssener U, Alexanderson A. Sickness absence, social relations and self-esteem - a qualitative study of the impact of relations with family, workmates, and friends among persons long-term sickness absent. 2008.

[17] Svensson T, Karlsson A, Nordqvist C, Alexanderson K. Shame-inducing encounters - negative emotional aspects of sick-absentees' interactions with rehabilitation professionals. Journal of Occupational Rehabilitation 2003;13(3):183-95.

[18] Müssener U, Upmark M, Festin K, Alexanderson A. Positive experiences of encounters with healthcare and social insurance professionals among people on long-term sick leave. Journal of Rehabilitation Medicine 2008;40:805-11.

[19] Upmark M, Borg K, Alexanderson A. Gender differences in experiencing negative encounters with healthcare. A study of long-term sickness absentees. Scandinavian Journal of Public Health 2007;35:577-84.

[20] Lynöe N, Wassel M, Olsson D, Alexanderson K. Respectful encounters and return to work: Empirical study of long-term sick-listed patients' experiences of Swedish healthcare. BMJ 2012;1(2):1-5.
[21] Östlund G, Alexanderson K, Cedersund E, Hensing G. It was really nice to have someone: Lay people with musculoskeletal disorders request supportive relationships in rehabilitation. Scandinavian Journal of Public Health 2001;29(4):285-91.

[22] Hallberg L. Qualitative methods in public health research. Hallberg L, editor. Lund: Studentlitteratur; 2002.

[23] Patton M. Qualitative research and evaluation methods. 3 ed. Thousand Oaks: Sage Publications; 1990.

[24] Srivastava P, Hopwood N. A practical iterative framework for qualitative data analysis. International Journal of Qualitative Methods 2009;8(1):76-84.

[25] Svensson T, Müssener U, Alexanderson K. Pride, empowerment and return to work: On the significance of positive social emotions in the rehabilitation of sickness absentees. Work: A Journal of Prevention, Assessment \& Rehabilitation 2006;27(1):57-65.

[26] Ilmarinen J. Aging workers. Occupational and Environmental Medicine 2001;58(8):546-52.

[27] Nordenfelt L, editor. The Concept of Work Ability. Bruxelles: P.I.E. Peter Lang; 2008.

[28] Nathanson D. Shame and pride - affect, sex, and the birth of the self. New York: Norton \& Company, Inc.; 1994.

[29] Taylor G. Pride, shame and guilt: Emotions of self-assessment. Oxford: Claredon Press; 1995.

[30] Scheff T. Microsociology: Discourse, Emotion, and Social Structure. Chicago: The University of Chicago Press; 1990.

[31] Söderberg E, Smeds M. Utvärdering av Försäkringsmedicinskt beslutsstöd - vägledning för sjukskrivning. Resultat för år 2009-2010. (in Swedish). Linköping: Institutionen för medicin och samhälle, Linköpings universitet, 2011.

[32] Steenstra I, Knol D, Bongers P. What works best for whom? An exploratory, subgroup analysis in a randomized, controlled trial on the effectiveness of a workplace intervention in low Back pain patients on return to work. Spine 2009;34(12):1243-9.

[33] Leinonen T, Pietiläinen O, Laaksonen M. Occupational social class and disability retirement among municipal employees the contribution of health behaviors and working conditions. Scandinavian Journal of Work and Environmental Medicine 2011;37(6):464-72.

[34] Krueger R, King J. The Focus Group Kit. London: SAGE Publications; 1998. 